\title{
Climate sensitivity of the ice cap of King George Island, South Shetland Islands, Antarctica
}

\author{
Wouter H. Knap, Johannes Oerlemans and Martin Cadée \\ Institute for Marine and Atmospheric Research Utrecht, Utrecht University, 3584 CC Utrecht, The Netherlands
}

\begin{abstract}
A two-dimensional vertically integrated ice-flow model has been used to simulate the current state of the ice cap of King George Island, South Shetland Islands, Antarctica, as well as the sensitivity of this state to climate change. The model was forced by an energy-balance model that generates the specific mass balance from climatological input data of two research stations. It proved difficult to simulate satisfactorily the entire geometry of the present-day ice cap. Nevertheless, it was possible to simulate a steary-state ice cap whose volume and areal extent approximate the (estimated) current situation. Several experiments have indicated that this state is highly sensitive to climate change. The model predicts that cooling by $1 \mathrm{~K}$ will increase the ice volume by $10 \%$ and warming by $1 \mathrm{~K}$ will decrease it by $36 \%$. A $10 \%$ change in precipitation will alter the ice volume by less than $8 \%$. Application of the IPCC-90 Business-as-Usual scenario leads to a $55 \%$ reduction in the ice volume by the year AD 2100, compared to the present-day situation. The response of the ice cap to warming is therefore totally different from the response of the main Antarctic ice sheet which is believed to gain mass by increasing temperatures.
\end{abstract}

\section{INTRODUGTION}

King George Island $\left(62^{\circ} \mathrm{S}, 58^{\circ} \mathrm{W}\right)$, the largest island of the South Shetland Islands, is situated near the northern extremity of the Antarctic Peninsula (Fig. 1). Since the island is situated so far north, its climate is dominated by westerly winds and is characterized by a rapid succession of eastward-moving low-pressure systems. These systems transport relatively warm and humid air towards the coasts of Antarctica. The relatively warm climate is responsible for significant ablation on the lower parts of the glaciers and ice caps during the summer. In such maritime conditions, glaciers and ice caps are very sensitive to temperature changes (Oerlemans, 1993). The idea that the King George Island ice cap may be sensitive to climate change was put forward earlier by Bintanja (1995a,b). His assumption was based on calculations of the surface energy balance in the ablation zone of Ecology Glacier, an outlet glacier near Arctowski Station (Fig. 1). Surface energy fluxes and ablation were calculated from meteorological data, collected during the summer of 1990-91 (Bintanja, 1995a, b). On the basis of these data, model calculations showed that a warming of $1 \mathrm{~K}$ increases the ablation by almost $15 \%$ on Ecology Glacier.

In this study, we attempt to give an idea of the sensitivity of King George Island as a whole. The smaller adjacent Nelson Island (Fig. 1) was included in the calculations. Ice flow was simulated by a two-dimensional vertically integrated model which is based on the model of Mahaffy (1976). She applied the model to the Barnes Ice Cap in Canada. Mass-balance profiles are simulated separately by an energy-balance model and are imposed on the ice-flow model. The energy-balance model was used earlier to simulate the mass balance of valley glaciers in the Alps and Norway and of the Greenland ice sheet (e.g. Oerlemans, 1992).

\section{DESCRIPTION OF THE MODEL}

The model consists of two parts: one part that simulates ice flow and another (independent) part that models the surface mass balance. Both parts will be described briefly. For further background on the ice-flow model and the mass-balance model, the reader is referred to Mahaffy (1976) and Oerlemans (1992), respectively.

The evolution of the ice cap is determined by conservation of ice mass. If the ice thickness is denoted by $H$, one has

$$
\frac{\partial H}{\partial t}=-\nabla \cdot \mathbf{F}+M
$$

Here $\mathbf{F}$ is the vertically integrated mass-flow vector and $M$ is the mass balance (length/time). The mass-flow vector is the product of the vertical mean velocity $\mathbf{u}$ and the ice thickness $H$. The velocity $\mathbf{u}$ consists of a deformation velocity $\mathbf{u}_{\mathrm{d}}$ and a sliding velocity $\mathbf{u}_{\mathrm{s}}$. On 


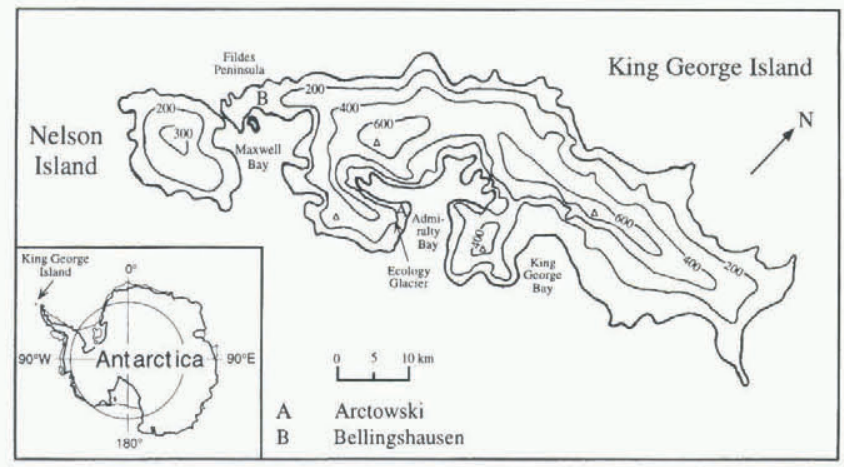

Fig. 1. Map of King George Island and Nelson Island with allitude contours in $m$ a.s.l. Two research stations are indicaled: Arctowski and Bellingshausen. The map has been taken from Barsch and others (1985), on the basis of sheet W6258 (1:200000), DOS, London 1968. The inset map shows the situation of the islands with respect to the Antarctic Peninsula and Antarctica.

the basis of Nye's generalized form of Glen's law (Nye, 1957 ) and the force balance, we used the following expression for $\mathbf{u}_{\mathrm{d}}$ :

$$
\mathbf{u}_{\mathrm{d}}=-\frac{2}{5} A(\rho g)^{3} H^{4}|\nabla(H+h)|^{2} \nabla(H+h) .
$$

Here $A$ is the flow parameter, $\rho$ is the ice density, $g$ is the gravitational acceleration and $h$ is the elevation of the bedrock above sea level. This equation is based on the following assumptions: (a) the ice deforms in planes parallel to the horizontal plane, (b) the longitudinal strain rates are much smaller than the shear strain rates and (c) the horizontal change in vertical velocity is much smaller than the vertical change in horizontal velocity. To obtain the total velocity $\mathbf{u}$, a sliding component was added. We followed the approach of Bindschadler (1983) by expressing the sliding velocity as

$$
\mathbf{u}_{\mathrm{s}}=\frac{A_{\mathrm{s}}(\rho g H)^{3}}{N-P}|\nabla(H+h)|^{2} \nabla(H+h) .
$$

$A_{\mathrm{s}}$ is the sliding parameter, $N$ is the ice overburden pressure and $P$ is the water pressure both in metres of water). Equations (1), (2) and (3) completely formulate the ice-flow model. The process of calving is modelled crudely: ice which flows beyond the current land-sea boundary is lost.

The mass balance $M$ (see Equation (1)) was calculated on the basis of the surface energy balance. The basic equations read

$$
M=\int_{\text {year }}\left\{(1-f) \min (0 ;-\varphi / L)+P^{*}\right\} \mathrm{d} t
$$

and

$$
\varphi=(1-\alpha) G+I_{\text {in }}+I_{\text {out }}+H_{\mathrm{s}}+H_{1} .
$$

The components of the energy balance $\varphi$ are the absorbed shortwave radiation ( $\alpha$ is albedo, $G$ is global radiation), incoming and outgoing longwave fluxes $\left(I_{\text {in }}\right.$ and $\left.I_{\text {out }}\right)$ and the turbulent fluxes of sensible and latent heat $H_{\mathrm{s}}$ and $H_{1}$ ). Melting occurs when the energy balance is positive. $L$ is the latent heat of melting. In Equation (4), $f$ is the fraction of meltwater that refreezes and does not contribute to mass loss. $P^{*}$ is the accumulation rate.

The formulation of the albedo is crucial to the sensitivity of the ice cap. So that significant feed-back mechanisms can be taken into account, the model generates the albedo internally. Relevant processes like metamorphosis of snow are incorporated in the model. Global radiation is parameterized in terms of atmospheric transmissivities, cloudiness and solar elevation. The incoming longwave radiation is calculated according to the approach of Kimball and others (1982) in which clear-sky and cloudy conditions are distinguished. The clear-sky term is parameterized (via atmospheric emissivity) as a function of water-vapour pressure, temperature and altitude. The contribution of clouds is basically parameterized as a function of cloud-base temperature and transmissivity of air between cloud and surface. Outgoing longwave radiation is calculated from the surface temperature, which is assumed to be at the melting point. The turbulent fluxes are calculated from temperature and vapour-pressure differences between surface and atmosphere. A constant turbulent-exchange coefficient is assumed $\left(14 \mathrm{~W} \mathrm{~m}^{-2} \mathrm{~K}^{-1}\right)$.

Meteorological input data needed to run the massbalance model are temperature and humidity at screen height, cloudiness and precipitation. Since little information is available about humidity and cloudiness, these quantities are taken to be constant with time. Precipitation depends on altitude. Sinusoidal variation in air temperature is assumed to generate daily and seasonal cycles. Further details about input are given in the next section.

\section{TECHNICAL ASPECTS AND INPUT DATA}

Equation (1) is solved numerically on a rectangular grid of $99 \times 45$ points. The grid-point distance is $1 \mathrm{~km}$. Spatial derivatives are approximated by central differences. The alternating direction implicit (ADI) scheme (e.g. Smith, 1978 ) is used for the integration in time. Due to lack of data, the bedrock topography was calculated by assuming that the ice cap is perfectly plastic. With a basal shear stress of $60 \mathrm{kPa}$, our calculations agree roughly with ice thicknesses measured by Orheim and Govorukha (1982). Since the mean ice thickness is relatively small $(100 \mathrm{~m})$, it is assumed that the bedrock does not react to the load of the ice mass.

To simulate the mass balance of King George Island, we used meteorological data obtained at Arctowski and Bellingshausen research stations (Martianov and RakusaSuszczewski, 1989) and on Ecology Glacier (Bintanja, 1995b). The data for the two research stations are the result of regular meteorological observations (eight measurements per $24 \mathrm{~h}$ ) during the period 1978 87. The measurements on Ecology Glacier, an outlet glacier near Arctowski station, were carried out during December 1990-January 1991 within the programme of the First Dutch Antarctic Expedition. Some input parameters for the mass-balance simulations are listed in Table 1. To take account of the fact that the measurements at the two research stations are made above an ice-free surface, the annual mean temperatures at Arctowski and Belling- 
Table 1. Climatological input parameters for the simulation of the reference mass-balance profiles for the areas of Arctoreski and Bellingshausen

Arctowski Bellingshausen

$\begin{array}{lcc}\text { Mean annual temperature } & -2.9 & -3.5 \\ \left({ }^{\circ} \mathrm{C}\right) & & \\ \text { Yearly amplitude }\left({ }^{\circ} \mathrm{C}\right) & 4.8 & 4.8 \\ \text { Lapse rate }\left({ }^{\circ} \mathrm{C} \mathrm{m}^{-1}\right) & 0.0062 & -0.0062 \\ \text { Cloudiness } & 0.77 & 0.89 \\ \text { Relative humidity }(\%) & 80 & 90 \\ \text { Annual precipitation }(\mathrm{m}) & 0.6+0.0022 h & 0.9+0.0017 \mathrm{~h}\end{array}$

shausen $\left(-1.8^{\circ}\right.$ and $-2.4^{\circ} \mathrm{C}$, respectively $)$ were lowered by $1.1^{\circ} \mathrm{C}$. This typical temperature difference between land and ice was derived from measurements on and near Ecology Glacier (Bintanja, 1992). The temperature lapse rate of $-6.2 \mathrm{~K} \mathrm{~km}^{-1}$ was obtained by a series of balloon soundings during the same period. The annual precipitation varies from about $0.5 \mathrm{~m}_{\text {year }}^{-1}$ at Arctowski (Martianov and Rakusa-Suszczewski, 1989) to approximately 2 mear $^{-1}$ at the summit (Zamoruyev, 1972). In all experiments discussed here the precipitation rate depends linearly on the altitude but it is constant throughout the year. The precipitation gradient of $2.3 \mathrm{~m} \mathrm{~km}^{-1}$ for the Arctowski area can be considered as extremely large (cf. $1.2 \mathrm{~m} \mathrm{~km}^{-1}$ for Nigardsbreen (Oerlemans, 1992) which is situated in the wet climate of western Norway).

The meteorological data listed in Table 1 give a reasonable simulation of mass-balance profiles for the Arctowski and Bellingshausen areas (Fig. 2). Unfortunately, there are too little data available to undertake an objective test. As a first guess, the two-dimensional distribution of the mass balance over the island was obtained by weighting the two mass-balance profiles. The weights were set at 1 on the ice divide and elsewhere they vary between 0 and 1 , dependent on the distance to the ice divide and to the coast. In this way, the climate of Bellingshausen dominates the area north of the ice divide and the climate of Arctowski dominates the southern parts of the island. This schematic approach is more or less justified by the prevailing large-scale circulation which affects mostly the north and northwestern parts of the island. The southern area is to some degree shielded from this activity.

\section{RESULTS}

\section{Simulation of the present-day ice cap}

In order to investigate the response of the ice cap to climate change, we defined an equilibrium state which
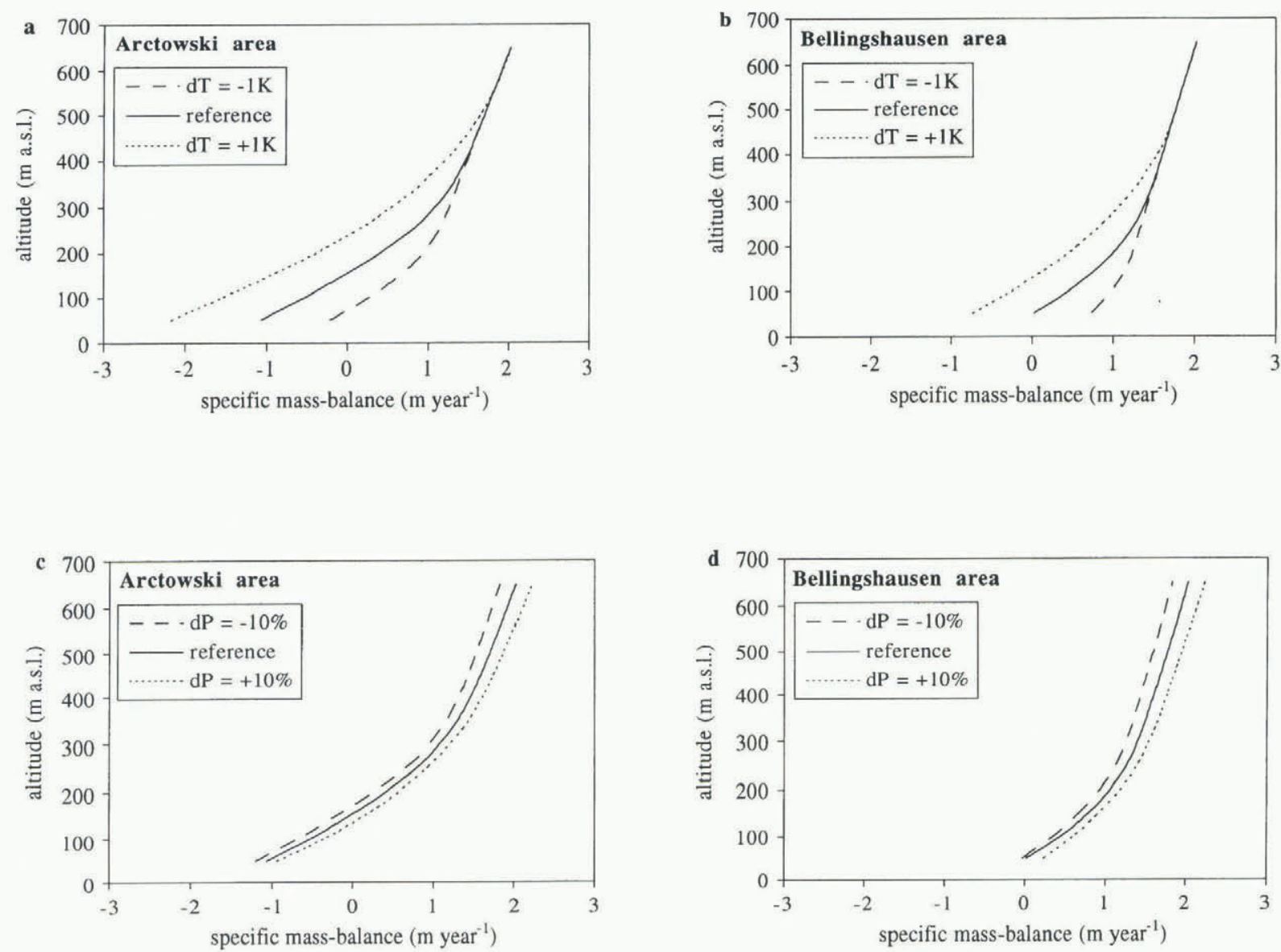

Fig. 2. Modelled mass-balance profiles of the areas of Arctowski and Bellingshausen. The climatological data in Table 1 define the reference profile (solid lines). The dolled lines indicate adjusted profiles for a warming or cooling $(\mathrm{d} T= \pm 1 \mathrm{~K}$; (a) and $(b))$ and a $10 \%$ change in precipitation $(\mathrm{d} P= \pm 10 \% ;(c)$ and $(d))$. 
Table 2. Characteristics of the present-day ice cap and several simulated ice caps in equilibrium. In all modelled cases the flow parameter $A=8 \times 10^{-24} \mathrm{~m}^{6} \mathrm{~s}^{1} \mathrm{~N}^{3}$. The constant sliding parameter $A_{\mathrm{s}}=6 \times 10^{-18} \mathrm{~m}^{8} \mathrm{~s}^{i} \mathcal{N}^{3}$. The reference state is defined by a varying sliding parameter, depending on the mass balance (see text)

\begin{tabular}{|c|c|c|c|}
\hline $\begin{array}{l}\text { Present } \\
\text { state }\end{array}$ & $\begin{array}{c}\text { No } \\
\text { sliding }\end{array}$ & $\begin{array}{l}\text { Constant } \\
\text { sliding }\end{array}$ & $\begin{array}{l}\text { Variable } \\
\text { sliding } \\
\text { (reference } \\
\text { state) }\end{array}$ \\
\hline 1.54 & 3.12 & 1.48 & 1.55 \\
\hline 1429 & 1471 & 1397 & 1402 \\
\hline 108 & 212 & 106 & 111 \\
\hline
\end{tabular}

agrees best with the current state of the ice cap. Calibration was done by adjusting the flow parameter $A$ and the sliding parameter $A_{\mathrm{s}}$ (Equations (2) and (3)). Areal extent of the ice cap, volume and mean thickness served as comparative quantities. Table 2 lists these quantities for the present-day ice cap derived from surface topography and based on the assumption that the ice cap is perfectly plastic). The ice volume is about $15 \%$ larger than the estimated ice volume in the European Alps in the mid 1970s.

The ice volume of the model ice cap with $A=8 \times$ $10^{-24} \mathrm{~m}^{6} \mathrm{~s}^{-1} \mathrm{~N}^{-3}$ and $A_{\mathrm{s}}=0$ (no sliding) is more than twice the ice volume of the present-day ice cap. Increasing the flow parameter to $10^{-22} \mathrm{~m}^{6} \mathrm{~s}{ }^{-1} \mathrm{~N}^{3}$ reduces the difference but overestimation is still significant $30 \%)$. An improvement was obtained by including basal sliding in the movement of the ice. Since the ice of King George Island is temperate, this is a logical step. The effective pressure was taken to be $80 \%$ of the ice overburden pressure $(N-P=0.8 \mathrm{~N}$; see Equation (3)). Table 2 shows that quite good results are obtained with $A=8 \times$ $10^{-24} \mathrm{~m}^{6} \mathrm{~s}^{-1} \mathrm{~N}^{3}$ and $A_{\mathrm{s}}=6 \times 10^{-18} \mathrm{~m}^{8} \mathrm{~s}^{-1} \mathrm{~N}^{3}$. The simulated areal extent of the ice is about $2 \%$ smaller than its current areal extent and the ice volume and mean ice thickness differ from the present state by only $4 \%$ and $2 \%$, respectively. The ice thickness is too small on the highest parts of the island and too large near the ice margin. Some improvement is obtained by introducing a sliding parameter that changes linearly with mass balance: $A_{\mathrm{s}}(M=-1 \mathrm{~m}$ w.e. $)=9 \times 10^{-18} \mathrm{~m}^{8} \mathrm{~s}^{-1} \mathrm{~N}^{-3}$ and $A_{\mathrm{s}}(M=+2 \mathrm{~m}$ w.e. $)=3 \times 10^{-18} \mathrm{~m}^{8} \mathrm{~s}^{-1} \mathrm{~N}^{-3}$. Table 2 shows that the differences between this state and the current state are fairly small. This state served as a reference state for climate experiments. Simulated surface altitudes are plotted against measured surface altitudes in Figure 3. It is clear that the agreement between the present-day and the modelled ice volume is caused partly by error cancellation: overestimation of the volume near the ice margin (low altitudes) is more or less compensated for by underestimation near the divide (high altitudes). Further experiments with different sliding parameterizations did not improve the results. Probably, the major reason for the discrepancy is the assumption that the

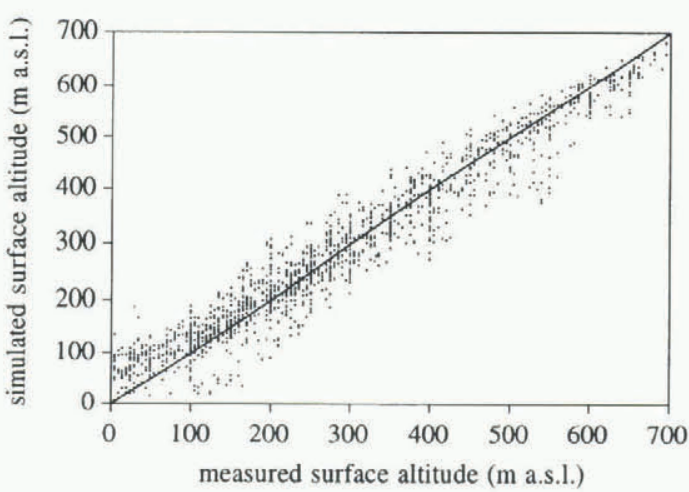

Fig. 3. Simulated surface altitude of the reference ice cap (see text and Table 2) against measured surface altitude.

longitudinal strain rates are negligible compared to the shear strain rates. In the centre and near the edges of the ice cap this is not true. At the same places, the (initial) assumption that the ice deforms plastically causes problems. Calculated ice thicknesses are too large where the surface slope is small and vice versa.

\section{Climate sensitivity}

In order to study the response of the ice cap to climate change, we perturbed the reference state with stepwise changes in mass balance. Calculations are continued until a new equilibrium state is reached. First, we consider
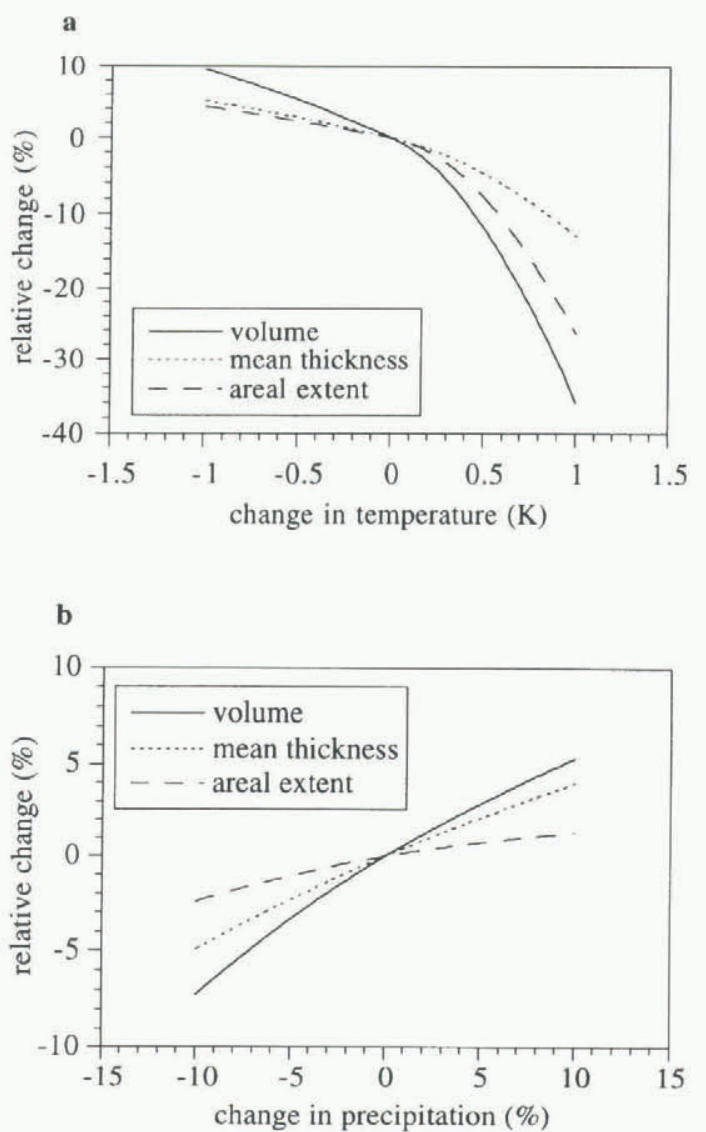

Fig. 4. Relative change in volume, thickness and areal extent of the reference ice cap as a function of a stepwise change in (a) annual temperature and (b) precipitation. All states are in equilibrium. 
(separate) changes in temperature (increase/decrease of $1 \mathrm{~K}$ ) and in precipitation (increase/decrease of $10 \%$ ). The effect of these changes on the mass-balance profiles is shown in Figure 2. The effect of a warmer or cooler climate is considerable and most pronounced on the lower parts of the ice cap. Mass balance is less affected by a change in precipitation and is influenced mainly at high altitude. The response of the ice cap in terms of volume, mean thickness and extent of ice is shown in Figure 4. Clearly, the configuration of the ice cap alters significantly with the imposed changes in temperature. For a $1 \mathrm{~K}$ cooling, an increase in ice volume of $10 \%$ is predicted. The ice-covered surface grows by $4 \%$ and almost reaches its maximum extent the model forbids extension beyond the current land-sea boundary). Mean ice thickness increases by about $5 \%$. The response of the ice cap to a warming of $1 \mathrm{~K}$ is spectacular: a $36 \%$ decrease in ice volume and a $26 \%$ decrease in areal extent are predicted. The reduction in mean ice thickness is $13 \%$. The ice dome of Nelson Island disappears almost entirely. Considering the relatively low altitude of the island, this is not surprising. The imposed warming hardly affects the areal extent of ice north of the divide of King George Island. However, the ice margin south of the divide retreats significantly. Calculations using larger temperature perturbations have shown that the ice cap eventually disappears if warming is more than $5 \mathrm{~K}$. As can be expected on the basis of the perturbed massbalance profiles, the imposed changes in precipitation have less effect than warming or cooling. Especially, the ice volume is influenced but by not more than $8 \%$.

Figure 5 gives an idea of the response time of the ice cap. Again, the reference state is perturbed with a $1 \mathrm{~K}$ warming or cooling. Apparently, a new equilibrium is reached more rapidly after cooling than after warming: the response time is 25 years in the case of cooling and 150 years in the case of warming. Basically, this feature is caused by the fact that the maximum ice extent is reached within several decades after the perturbation. Once this maximum has been reached, the increased calving flux controls the ice volume to a large extent and prevents the ice cap from extensive growth $(\mathrm{d} V / \mathrm{d} t \approx 0)$. Clearly, the crude formulation of calving is essential in this reasoning.

\section{The ice cap in the next century?}

There is considerable uncertainty in predictions of future climate. Several scenarios are outlined in the Intergovernmental Panel on Climate Change (IPCC) report on climate change, which are based on future man-made emissions of greenhouse gases (Bretherton and others, 1990). One of these is the so-called Business-as-Usual $(\mathrm{BaU})$ scenario. According to this scenario, few or no steps are taken to limit man-made emissions. Compared to the situation of 1990 , the scenario predicts a doubling of the atmospheric $\mathrm{CO}_{2}$ concentration by the end of the next century. Concentrations of the effective greenhouse gases $\mathrm{CH}_{4}$ and CFC-11 would be doubled before AD 2050 . The average rate of increase of global mean temperature during the next century is estimated at $0.3 \mathrm{~K}$ per decade. This implies an increase of $3 \mathrm{~K}$ above the level of 1990 before the end of the next century. We applied the $\mathrm{BaU}$ scenario to obtain an impression of the response of the ice

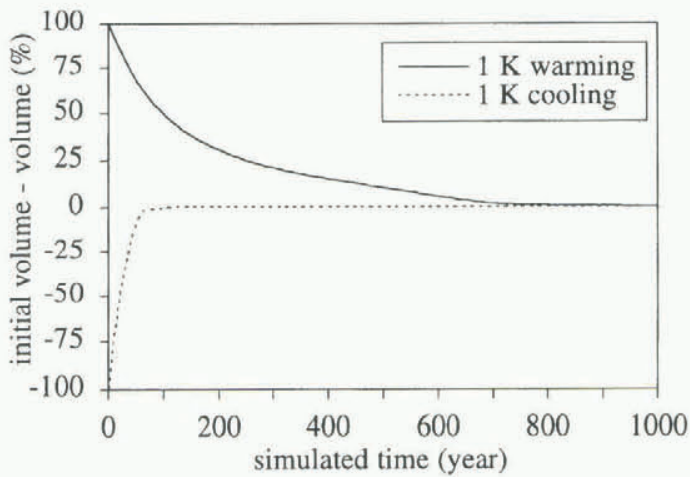

Fig. 5. Time-dependent development to new equilibrium, in response to a $1 \mathrm{~K}$ warming or cooling. The vertical axis represents the relative volume that is gained (lost) in the case of cooling (warming). The initial state is the reference state (see text and Table 2).

cap to a possible change in climate during the next century. In order to allow for a less dramatic change, simulations were undertaken with half the temperature increase that is predicted by the $\mathrm{BaU}$ scenario $(0.5 \times \mathrm{BaU})$. This situation is close to IPCC scenario $\mathrm{C}$, which assumes some limitation of the emission of greenhouse gases. Two runs per scenario were carried out: one with constant precipitation and one with a $5 \% \mathrm{~K}^{-1}$ increase in precipitation. Again, the initial situation is the equilibrium reference state as described before. $t=0$ is taken as 1990 and the simulation continues until AD 2100. Changes in ice volume are presented in Figure 6. This figure demonstrates that the $\mathrm{BaU}$ scenario results in a rapid reduction in the volume of the ice cap. Large changes are predicted, particularly in the second half of the 21 st century. By AD 2050 the ice volume has decreased by $10-20 \%$ relative to the reference volume and by $\mathrm{AD}$ 2100 the ice volume is roughly halved. The $0.5 \times \mathrm{BaU}$ scenario is obviously less radical: by AD 2050 the ice volume has decreased by $5-10 \%$ of the original volume and by AD 2100 this percentage is $15-20 \%$. The figure

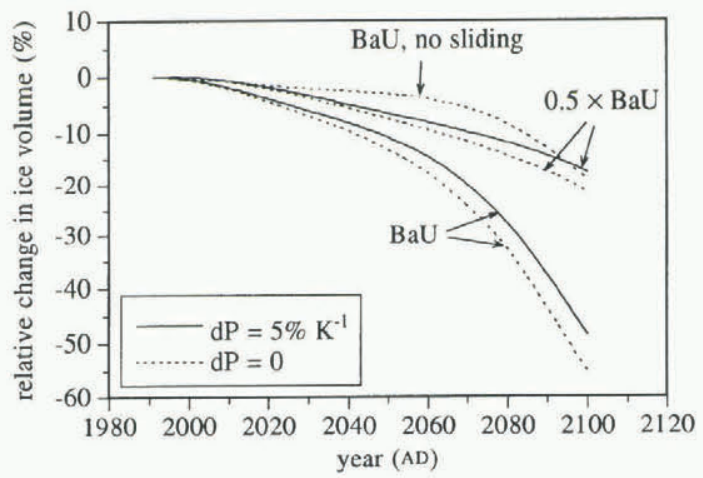

Fig. 6. Time-dependent response of the reference ice volume to a gradual temperature increase (with and without increase in precipitation) as predicted by the IPCC-90 Business-as-Usual scenario $(\mathrm{Ba} U)$. The $0.5 \times \mathrm{BaU}$ curves give the response to half of this temperature increase. The uppermost curve starts from an initial state without basal sliding. To highlight the effect of climate change only, this simulation continues without basal sliding. 
demonstrates that the ice-volume decrease is not significantly depressed by a $5 \% \mathrm{~K}^{1}$ increase in precipitation.

The response of the ice cap to climate change is dependent both on its initial state and on the properties of ice flow. To illustrate this, the $\mathrm{BaU}$ scenario was applied to an initial state in which basal sliding does not contribute to the flow of the ice. Compared to the reference state, this ice cap is too thick (high) and its edges are too steep. To focus on the effect of climate change only, the simulation was performed continuously without basal sliding. The result of this experiment is shown in Figure 6. Relative mass loss reduces from 55\% to about $19 \%$. Absolute mass loss is obviously reduced less significantly (from $7.8 \times 10^{10}$ to $5.6 \times 10^{10} \mathrm{~m}^{3}$ ) due to the different initial conditions. The reduction in mass loss is caused basically by the different flow characteristics and by the difference in hypsometry of the two reference states.

\section{SUMMARY AND CONCLUSION}

The present-day ice cap of King George Island was represented by a steady-state form that was simulated by a two-dimensional vertically integrated ice-flow model. Bedrock topography was estimated by assuming perfect plasticity of the ice. Mass-balance profiles were simulated by an energy-balance model and were superposed on the flow model. Climatological data from two research stations served as input for the energy-balance model. Ice volume and areal extent of the steady-state ice cap closely resemble those of the present-day ice cap. However, it proved difficult to simulate the shape of the ice cap satisfactorily. Closer agreement with the observed surface elevation might be obtained by adjusting the calculated bedrock topography. This adjustment may increase the mean ice thickness to a more realistic value.

The steady-state ice cap was subjected to several experiments simulating climate change. A temperature increase of $1 \mathrm{~K}$ reduces the ice volume by as much as $36 \%$ and large parts of the island lose their ice cover. Especially, the ice margin of the southern part of the island retreats significantly. The ice cap disappears entirely if the temperature increase is larger than $5 \mathrm{~K}$. The effect of a $1 \mathrm{~K}$ cooling is less drastic: the ice volume increases by about $10 \%$. It is clear that this number depends critically on the crude treatment of calving: the model prescribes that ice cannot flow beyond the present-day boundary between land and sea. The response of the ice cap to a $10 \%$ change in precipitation is modest: not more than $8 \%$ of the ice volume is gained or lost.

In order to study the response of the ice cap to possible future warming, we perturbed the steady state by a gradual temperature increase at an average rate of $0.3 \mathrm{~K}$ per decade (IPCC-90 Business-as-Usual (BaU) scenario). The model predicts that the ice volume will be reduced by $13 \%$ in $\mathrm{AD} 2050$ and by $55 \%$ in $\mathrm{AD} 2100(49 \%$ in the case of a $5 \% \mathrm{~K}^{-1}$ increase in precipitation). It should be noted that the $\mathrm{BaU}$ scenario refers to changes in global mean temperature and that the local climate of King George Island may show a different temperature course.

It is clear that the response of the ice cap to climate change is dependent on its initial conditions and its flow characteristics. This was illustrated by an experiment in which basal sliding did not contribute to the flow of ice. Nevertheless, all the experiments presented here indicate that the ice cap of King George Island is very sensitive to climate change. Reduction in the ice volume is totally different from the response of the main Antarctic ice sheet to warming, which is believed to gain mass in the case of increasing temperatures (Huybrechts and Oerlemans, 1990). Since the relatively warm climate of King George Island is representative of the South Shetland Islands and possibly for the entire northern part of the Antarctic Peninsula, it is plausible that the glaciers and ice caps in this area are also very sensitive to climate change.

\section{ACKNOWLEDGEMENTS}

R. Bintanja, W. Greuell, H. Jiskoot and R. S. W. van de Wal are thanked for useful comments.

\section{REFERENCES}

Barsch, D., W. -D. Blümel, W. -A. Flügel, R. Mäusbacher, G. Stäblein and W. Zick. 1985. Untersuchungen zum Periglazial auf der KönigGeorg-Insel Südshetlandinseln/Antarktika. Deutsche physiogeographische Forschungen in der Antarktis. Bericht über die Kampagne 1983/84. Ber. Polarforsch. 24.

Bindschadler, R. 1983. The importance of pressurized subglacial water in separation and sliding at the glacier bed. J. Glaciol., 29 101), 3-19.

Bintanja, R. 1992. Glaciological and meteorological investigations on Ecology Glacier, King George Island, Antarctica summer 1990 1991). Circumpolar 7., 7, 59-71.

Bintanja, R. 1995a. The Antarctic ice sheet and climate. The Hague, CIPGegevens Koninklijke Bibliotheek. (Ph.D. thesis.

Bintanja, R. 1995b. The local surface energy balance of the Ecology Glacier, King George Island, Antarctica: measurements and modelling. Antarct. Sci., 7 (3), 315-325.

Bretherton, F. P., K. Bryan and J. D. Woods. 1990. Time-dependent greenhouse-gas-induced climate change. In Houghton, J. T., G.J. Jenkins and J.J. Ephraums, eds. Climale change: the IPCC scientific assessment. Cambridge, etc., Cambridge University Press, 173-193.

Huybrechts, P. and J. Oerlemans, 1990. Response of the Antarctic ice sheet to future greenhouse warming. Climate Dyn., 5 2), 93-102.

Kimball, B. A., S. B. Idso and J.K. Aase. 1982. A model of thermal radiation from partly cloudy and overcast skies. Water Resour. Res., 18. $931-936$.

Mahaffy, M.W. 1976. A three-dimensional numerical model of ice sheets: tests on the Barnes Ice Cap, Northwest Territories. 7. Geophys. Res., 81 6), 1059-1066.

Martianov, V. and S. Rakusa-Suszczewski. 1989. Ten years of climate observations at the Arctowski and Bellingshausen stations (King George Is., South Shetlands, Antarctica). In Breymeyer, A., ed. Global change regional research centres: scientific problems and concept developments. Warsaw, 80-87

Nye, J. F. 1957. The distribution of stress and velocity in glaciers and icesheets. Proc. R. Soc. London, Ser. A, 239 (1216), 113-133.

Oerlemans, J. 1992. Climate sensitivity of glaciers in southern Norway: application of an energy- balance model to Nigardsbreen, Hellstugubreen and Alfotbreen. J. Glaciol., 38 129), 223-232.

Oerlemans, J. 1993. Modelling of glacier mass balance. In Peltier, W. R. ed. Ice in the climate system. Berlin, etc., Springer-Verlag, 101-116. (NATO ASI Series I: Global Environmental Change 12.

Orheim, O. and L.S. Govorukha. 1982. Present-day glaciation in the South Shetland Islands. Ann. Glaciol., 3, 233-238.

Smith, G. D. 1978. Numerical solutions of partial differential equations: finite difference methods. Oxford, etc., Clarendon Press.

Zamoruyev, V. V. 1972. Rezul'taty glyatsiologicheskikh nablyudeniy na stantsii Bellingsgauzen v 1968g. [Results of glaciological observations at "Bellingshausen" station in 1968]. Sovetskaya Antarkticheskaya Ekspeditsiya Trudy, 55, 135-144. 